\title{
DISTRIBUTION OF DRUG SENSITIVE TUBERCULOSIS BY SEX, AGE GROUPS AND TYPE OF DISEASE IN DS- TB POPULATION OF DISTRICT D.I.KHAN, PAKISTAN
}

\author{
Abshar Khan, (D) Altaf Hussain, ID Mubashir Wahab, DAbdur Rehman, iD Shah Abdul Latif, \\ DSyed Wasif Ali Naqvi, (D) Mamoon Farooq, (DMuhammad Zubair \\ Students, Department of Community Medicine, Gomal Medical College, D.I.Khan, Pakistan
}

\begin{abstract}
Background: Tuberculosis (TB) is the $10^{\text {th }}$ leading cause of death globally and is leading cause of death from a single infectious disease. The objectives of our study were to determine the distribution of drug sensitive tuberculosis (DS-TB) by sex, age groups and type of disease in DS-TB population of District D.I.Khan, Pakistan.

Materials \& Methods: This cross-sectional study was conducted in Department of Community Medicine, Gomal Medical College, D.I.Khan, Pakistan from January 5, 2021 to January 25, 2021. The data of 3,916 patients was retrieved from District Health Office, D.I.Khan for the period from January 1, 2019 to December 31, 2020. Sex, age groups and type of disease were categorical variables and analyzed by count and percentage with $\mathrm{Cl}$ at $95 \%$ CL. Distribution of DR-TB by sex, age groups and type of disease was analyzed separately by chi-square goodness-of-fit test at alpha 05 .
\end{abstract}

Results: Out of 3,916 patients with DS-TB, women 2,110 (53.88\%, 95\% Cl 52.32-55.44) were more than men 1,806 $(46.12 \%, 95 \% \mathrm{Cl} 44.55-47.67)$, with most common age group of $15-44$ years $1,948(49.74 \%, 95 \% \mathrm{Cl} 48.17-51.31)$, and with more pulmonary $2,877(73.47 \%, 95 \% \mathrm{Cl} 72.08-74.85 \%)$ than extrapulmonary $1,039(26.53 \%, 95 \% \mathrm{Cl}$ 25.14-27.91) cases. Our observed prevalence of DS-TB in men was lower $46.12 \%$ than expected $51.72 \%$ and in women it was higher $53.88 \%$ than expected $48.28 \%(p<.00001)$. Our observed distribution of DS-TB in different age groups was not similar to expected $(p<.00001)$. Our observed prevalence of pulmonary TB was lower $73.47 \%$ than expected $80.35 \%$ and in extrapulmonary TB it was higher $26.53 \%$ than expected $19.65 \% \quad(p<.00001)$.

Conclusions: Drug sensitive tuberculosis was more common in women than men in DS-TB population of District D.I.Khan, Pakistan. It was highest in age group 15-44 years and higher for pulmonary TB than extrapulmonary TB. Our observed prevalence in men was lower than expected and in women it was higher than expected. Our observed prevalence for drug sensitive TB in various age groups was different than expected. Our observed prevalence for pulmonary TB was lower than expected and for extrapulmonary TB it was higher than expected. KEY WORDS: Tuberculosis; Pulmonary Tuberculosis; Extrapulmonary Tuberculosis; Sex; Men; Women; Age Groups; Adult; Prevalence; Incidence.

Cite as: Khan A, Hussain A, Wahab M, Rehman A, Latif SA, Naqvi SWA, et al. Distribution of drug sensitive tuberculosis by sex, age groups and type of disease in DS-TB population of District D.I.Khan, Pakistan. Gomal J Med Sci 2021 Apr-Jun; 19(2):66-72. https://doi.org/10.46903/gjms/19.02.1012

\section{INTRODUCTION}

1.1 Background: Tuberculosis (TB) is the $10^{\text {th }}$ commonest cause of death globally and is the top cause of death from a single communicable disease.

\section{Corresponding Author: \\ Altaf Hussain \\ Student, Gomal Medical College \\ D.I.Khan, Pakistan \\ E-mail: altafagra6@gmail.com}

$\begin{array}{ll}\text { Date Submitted: } & 30-01-2021 \\ \text { Date Revised: } & 28-03-2021 \\ \text { Date Accepted: } & 29-03-2021\end{array}$

Worldwide in 2018, approximately 10 million people were involved in tuberculosis. It caused 1.2 million deaths in HIV non-infected persons and 251,000 deaths in HIV infected persons. ${ }^{1}$

In 2018, TB was most prevalent in adult males $57 \%$, then adult females $32 \%$ and then children $11 \%$. The prevalence of TB in HIV patients was $8.6 \%$. Eight countries contribute to its $2 / 3$ rd magnitude globally; India 27\%, Indonesia 8\%, China 9\%, Philippines 6\%, Pakistan 6\%, Nigeria 4\%, Bangladesh 4\% and South Africa $3 \% .^{1}$

Barreto, et al. ${ }^{2}$ from Brazil reported 896,314 cases for the period from 2010-2019 in a nationwide study, out 
of which $613,545(68.45 \%)$ were men and 282,769 $(31.55 \%)$ women, and $15,666(1.74 \%)$ were in age group <10 years, $16,589(18.14 \%)$ in $10-24$ years, $632,211(70.53 \%)$ in $25-64$ years and $82,112(9.16 \%)$ in $>65$ years.

Pang, et al. ${ }^{3}$ from Beijing, China reported 20,534 hospitalized TB patients for the period from January 2008-December 2017, including 12,846 (62.56\%) pulmonary TB (PTB), 6,433 (31.33\%) extrapulmonary TB (EPTB) cases and 1,255 (6.11\%) concurrent PTB \& EPTB.

Alene, et al. ${ }^{4}$ from Hunan, China showed 481 patients of MDR \& XDR TB for the period from 2011 to 2014 , including 340 (70.7\%) males and $141(29.3 \%)$ females.

Aysel, et al. ${ }^{5}$ from Van city, Turkey retrospectively reviewed medical records of 411 TB patients for the period from January 2010-July 2014, including 221 (53.77\%) men and 190 (46.23\%) women, and 208 (50.6\%) PTB and 203 (49.4\%) EPTB cases.

Venkatesh, et al. ${ }^{6}$ from Gorakhpur, India reported 157 cases for the period from November 2015 to October 2016 as 108 (68.8\%) males and 49 (31.2\%) females, and $80(51 \%)$ in age group 18-29 years, 45 (28.7\%) in $30-40$ and $32(20.3 \%)$ in $>40$ years.

According to data for year 2018 from National TB Control Program (NTP) of Pakistan, 360,019 cases of TB were reported in Pakistan, including 186,195 $(51.72 \%)$ men and 173,824 (48.28\%) women, and $47,804(13.28 \%)$ in age groups in 0-14 years, 180,303 $(50.08 \%)$ in $15-44$ years, $92,825(25.78 \%)$ in $45-64$ years and $39,087(10.86 \%)$ in age group $>65$ years, and 289,265 (80.35\%) PTB and 70,754 (19.65\%) EPTB. $^{7}$

Out of high prevalent countries, Pakistan is on $5^{\text {th }}$ position for DS-TB and also on $5^{\text {th }}$ for DR-TB. Incidence, prevalence and mortality were estimated as $267 / 100,000,341 / 100,000$ and $27 / 100,000$ population respectively with approximately 525,000 new tuberculosis patients each year. ${ }^{8}$

Akhtar, et al. ${ }^{9}$ reported distribution of 1,250 TB cases from Lahore, Pakistan for the period from January 2010 to June 2014 as 664 (53.12\%) men and 586 $(46.88 \%)$ women, and 31 (2.48\%) in age group 0-14 years, $996(79.68 \%)$ in 15-45 years and 223 $(17.84 \%)$ in $>46$ years, and 1,231 (98.48\%) PTB \& 19 (1.52\%) EPTB.

Wahab, et al. ${ }^{10}$ from Peshawar, Pakistan for years 2006 to 2007 reported 30 TB cases, including 17 $(56.7 \%)$ males and $13(43.3 \%)$ females, and four $(13.3 \%)$ in age group $<20$ years, $18(60 \%)$ in $20-40$ and $8(26.7 \%)$ in $>40$ years.

Ashraf, et al. ${ }^{11}$ from Bannu, Pakistan reported 133 TB cases for the period from January through December 2018 as $57(42.86 \%)$ men and $76(57.14 \%)$ women, and zero in $<5$, six $(4.51 \%)$ in $5-14,39(29.32 \%)$ in
$15-30,16(12.03 \%)$ in $31-45,46(34.59 \%)$ in $46-60$ and $26(19.55 \%)$ in $>60$ years age groups.

Zeeshan, et al. ${ }^{12}$ from D.I.Khan, Pakistan reported 286 drug resistance TB cases for the period from September 2013 to December 2019. Out of which 123 (43\%) were men and 163 (57\%) women, and eight $(2.80 \%)$ in age group $0-14$ years, $172(60.14 \%)$ in age group 15-44 years, 106 (37.06\%) in > 45 years, and $282(98.60 \%)$ as PTB and four (1.40\%) as EPTB.

1.2 Research problems (RPs), Knowledge Gaps (KGs) \& Rationale: Unawareness of distribution of drug sensitive tuberculosis (DS-TB) by sex, age groups and type of disease in DS-TB population of District D.I.Khan, Pakistan were our three RPs. We could not retrieve the relevant data from various databases/ search engines. Unawareness of these information were our three KGs. What is the distribution of drug sensitive tuberculosis by sex, age groups and type of disease in DS-TB population of District D.I.Khan were our three RQs?

The rationale of our study was to answer these three $R Q s$, fill these three KGs and hence solve our three RPs. We have adopted "Marwat's Logical Trajectory of Research Process" in this project. ${ }^{13-18}$

1.3 Research objectives: To determine the;

RO 1: distribution of DS-TB by sex in DS-TB population of District D.I.Khan.

RO 2: distribution of DS-TB by age groups in DS-TB population of District D.I.Khan.

RO 3: distribution of DS-TB by type of disease in DS-TB population of District D.I.Khan.

\subsection{Research Hypotheses}

$\mathrm{H}_{\mathrm{O} 1}$ : The sample and population distribution of DSTB by sex is same in DS-TB population of District D.I.Khan.

$\mathrm{H}_{\mathrm{O} 2}$ : The sample and population distribution of DSTB by age groups is same in DS-TB population of District D.I.Khan.

$\mathbf{H}_{\mathrm{O} 3}$ : The sample and population distribution of DSTB by type of disease is same in DS-TB population of District D.I.Khan.

\section{MATERIALS AND METHODS}

2.1 Design, Setting and Duration: We carried out this cross-sectional study in the Department of Community Medicine, Gomal Medical College, D.I.Khan, Pakistan from January 5, 2021 to January 25, 2021. This was a project of fourth year MBBS students under supervision of Dr. Muhammad Marwat.

2.2 Population \& sampling: District Health Office, D.I.Khan provides diagnostic and curative services for tuberculosis to population of District D.I.Khan. The population of District D.I.Khan was $1,627,132$ in 2017 census. It was presumed to be 1.9 million for 2019. TB prevalence in Pakistan was estimated 
for year 2019 as 341 per 100,000 (0.341\%). With margin of error $0.1824 \% \%, 95 \% \mathrm{CL}$ and assumed prevalence of $0.341 \%$ of DS-TB, a sample size of 3,916 was calculated. ${ }^{19}$

2.3 Procedure of conduct: The data of 3,916 patients was retrieved from computer record of DS-TB Center, District Health Office, D.I.Khan for duration from 01-01-2019 to 31-12-2020.

2.4 Data collection plan: Data was retrieved for these three variables (groups); sex (men and women), age groups (0-14, 15-44, 45-64, 65+ years) and types of disease (pulmonary and extrapulmonary). Sex and type of disease were nominal data, while age groups were ordinal data.

\subsection{Data Analysis Plan}

2.5.1 Descriptive analysis and estimation of parameters: These three variables were analyzed by count and percentage for the sample. The sample data was inferred on to the population as confidence intervals at $95 \% \mathrm{CL}$, using normal approximation method. ${ }^{20}$

2.5.2 Testing of Hypotheses: The three null hy- potheses $\left(\mathrm{H}_{01}-\mathrm{H}_{03}\right)$ were verified by chi-square goodness-of-fit test each. Observed counts (O), expected counts $(E), O-E, O-E^{2}, \chi^{2}, \Sigma \chi^{2}$, degree of freedom and $p$-value are given at a $.05 .{ }^{21}$

\section{RESULTS}

3.1 Descriptive analysis and estimation of parameters

3.1.1 Distribution of DS-TB by Sex (RQ 1): Out of 3,916 cases having DS-TB, $1,806(46.12 \%, 95 \% \mathrm{Cl}$ $44.55-47.67)$ were men and $2,110(53.88 \%, 95 \% \mathrm{Cl}$ $52.32-55.44)$ women. The prevalence was higher in women than men. (Table 3.1.1)

3.1.2 Distribution of DS-TB by age groups (RQ 2): Maximum cases of DS-TB $1,948(49.74 \%, 95 \% \mathrm{Cl}$ 48.17-51.31) were in age group 15-44 years. (Table 3.1.2)

3.1.3 Distribution of DS-TB by type of disease (RQ 3): We had 2,877 (73.47\%, 95\% Cl 72.08-74.85\%) patients of pulmonary and $1,039(26.53 \%, 95 \% \mathrm{Cl}$ 25.14-27.91) patients of extrapulmonary tuberculosis. PTB was more common than extrapulmonary. (Table 3.1.3)

Table 3.1.1: Distribution of drug sensitive TB by sex in DS-TB population of District D.I.Khan $(n=3,916)$

\begin{tabular}{|l|l|c|c|c|c|}
\hline \multirow{2}{*}{ Variable } & \multirow{2}{*}{ Attributes } & \multicolumn{2}{|c|}{ Sample analysis } & \multicolumn{2}{c|}{$95 \%$ Cl for proportion } \\
\cline { 3 - 6 } & & Count & Percentage & Lower & Upper \\
\hline \multirow{2}{*}{ Sex } & Men & 1806 & 46.12 & 44.56 & 47.68 \\
\cline { 2 - 6 } & Women & 2110 & 53.88 & 52.32 & 55.44 \\
\hline \multicolumn{2}{|c|}{ Total } & 3,916 & $100 \%$ & \multicolumn{2}{c|}{ Population parameters } \\
\hline
\end{tabular}

Table 3.1.2: Distribution of drug sensitive TB by age groups in DS-TB population of District D.I.Khan $(n=3,916)$

\begin{tabular}{|l|l|c|c|c|c|}
\hline \multirow{2}{*}{ Variable } & \multirow{2}{*}{ Attributes } & \multicolumn{2}{c|}{ Sample analysis } & \multicolumn{2}{c|}{$95 \%$ Cl for proportion } \\
\cline { 3 - 6 } & & Count & Percentage & Lower & Upper \\
\hline \multirow{4}{*}{$\begin{array}{l}\text { Age groups } \\
\text { Years) }\end{array}$} & $0-14$ & 299 & 7.64 & 6.84 & 8.51 \\
\cline { 2 - 6 } & $15-44$ & 1948 & 49.74 & 48.18 & 51.31 \\
\cline { 2 - 6 } & $45-64$ & 1076 & 27.48 & 26.10 & 28.89 \\
\cline { 2 - 6 } & $65+$ & 593 & 15.14 & 14.05 & 16.30 \\
\hline \multicolumn{2}{|c|}{ Total } & 3,916 & $100 \%$ & \multicolumn{2}{c}{ Population parameters } \\
\hline
\end{tabular}

Table 3.1.3: Distribution of drug sensitive TB by type of disease in DS-TB population of District D.I.Khan $(n=3,916)$

\begin{tabular}{|l|l|c|c|c|c|}
\hline \multirow{2}{*}{ Variable } & \multirow{2}{*}{ Attributes } & \multicolumn{2}{|c|}{ Sample analysis } & \multicolumn{2}{c|}{$95 \%$ Cl for proportion } \\
\cline { 3 - 6 } & & Count & Percentage & Lower & Upper \\
\hline \multirow{2}{*}{ Type of disease } & Pulmonary & 2877 & 73.47 & 72.06 & 74.83 \\
\cline { 2 - 5 } & Extrapulmonary & 1039 & 26.53 & 25.17 & 27.94 \\
\hline \multicolumn{2}{|c|}{ Total } & 3,916 & $100 \%$ & \multicolumn{2}{|c|}{ Population parameters } \\
\hline
\end{tabular}




\subsection{Hypotheses Testing}

3.2.1 Distribution of DS-TB by $\operatorname{sex}\left(R Q 1 \& \mathrm{H}_{01}\right)$ : Our observed counts for men versus women were $1,806: 2,110(n=3,916)$ against expected counts of $186,195: 173,824$ from 360,019 cases of TB from all over Pakistan for the year 2018. ${ }^{7}$ With difference in denominators, the comparison was not logical. Therefore expected counts and expected percentages were adjusted for our sample size of 3,916 . The expected counts of $186,195: 173,824$ were replaced by $2,025.28: 1,890.72$ (adjusted expected). Adjusted expected percentages were same as expected percentages. (Table 3.2.1.1)

Test of significance gave us $p$-value $<.00001$, rejecting $\mathrm{H}_{01}$, which shows that our observed prevalence of DS-TB $46.12 \%$ in men was lower than expected (adjusted) $51.72 \%$ \& for women $53.88 \%$ it was higher than expected (adjusted) $48.28 \%$ from NTP Pakistan ${ }^{7}$ data for year 2018. (Table 3.2.1.2)

3.2.2 Distribution of DS-TB by age groups ( $R Q 2$ \& $\left.H_{02}\right)$ : Our observed counts for age groups (in years) of 0-14:15-44:45-64: $\geq 65$ were 299:1,948:1,076:593 $(n=3,916)$ against expected counts of 47,804:180,303:92,825:39,087 from 360,019 cases of TB from all over Pakistan for year $2018 .^{7}$ With different denominators, comparison was not logical. Therefore expected counts and expected percentages were adjusted for our sample size of 3,916 . The expected counts of $47,804: 180,303: 928,25: 39,087$ were replaced by 519.97:1,961.20:1,009.68:425.16 (adjusted expected). Adjusted expected percentages were same as expected percentages. (Table 3.2.2.1)

Test of significance gave us $p$-value $<.00001$, rejecting $\mathrm{H}_{02}$, which shows that our observed prevalence of DS-TB in different age groups was not similar to

Table 3.2.1.1: Observed, expected and adjusted expected counts and percentages for distribution of drug sensitive TB by sex in DS-TB population of District D.I.Khan $(n=3,916)$

\begin{tabular}{|l|c|c|c|c|c|c|}
\hline Sex & $\begin{array}{c}\text { Observed } \\
\text { counts }\end{array}$ & $\begin{array}{c}\text { Observed } \\
\text { \%ages }\end{array}$ & $\begin{array}{c}\text { Expected } \\
\text { counts }\end{array}$ & Expected \%ages & $\begin{array}{c}\text { Adjusted expected } \\
\text { counts }\end{array}$ & $\begin{array}{c}\text { Adjusted expect- } \\
\text { ed \%ages }\end{array}$ \\
\hline Men & 1806 & $\begin{array}{c}1806 * 100 / 3916 \\
=46.12 \%\end{array}$ & 186195 & $\begin{array}{c}186195^{*} 100 / 360019 \\
=51.72 \%\end{array}$ & $\begin{array}{c}186195 * 3916 / 360019 \\
=2025.28\end{array}$ & $\begin{array}{c}2025.28 * 100 / 3916 \\
=51.72 \%\end{array}$ \\
\hline Women & 2110 & $\begin{array}{c}2110 * 100 / 3916 \\
=53.88 \%\end{array}$ & 173824 & $\begin{array}{c}173824 * 100 / 360019 \\
=48.28 \%\end{array}$ & $\begin{array}{c}173824 * 3916 / 360019 \\
=1890.72\end{array}$ & $\begin{array}{c}1890.72 * 100 / 3916 \\
=48.28 \%\end{array}$ \\
\hline Total & 3916 & $100 \%$ & 360019 & $100 \%$ & 3916 & $100 \%$ \\
\hline
\end{tabular}

Table 3.2.1.2: Observed vs. expected distribution of drug sensitive TB by sex in DS-TB population of District D.I.Khan $(n=3,916)$

\begin{tabular}{|l|c|c|c|c|c|c|c|c|}
\hline Sex & Observed count & Expected count & O-E & $(\mathrm{O}-\mathrm{E})^{2}$ & $\chi^{2}$ & $\Sigma \chi^{2}$ & d.f. & p-value \\
\cline { 1 - 6 } Men & 1806 & 2025.28 & -219.28 & 48083.72 & 23.74 & \multirow{2}{*}{49.17} & \multirow{2}{*}{1} & $<.00001$ \\
\cline { 1 - 5 } Women & 2110 & 1890.72 & 219.28 & 48083.72 & 25.43 & & & \\
\hline Total & 3916 & 3916 & 00 & & & & \\
\hline
\end{tabular}

Table 3.2.2.1: Observed, expected and adjusted expected counts and percentages for distribution of drug sensitive TB by age groups in DS-TB population of District D.I.Khan $(n=3,916)$

\begin{tabular}{|l|c|c|c|c|c|c|}
\hline Age groups & $\begin{array}{c}\text { Observed } \\
\text { counts }\end{array}$ & $\begin{array}{c}\text { Observed } \\
\text { \%ages }\end{array}$ & $\begin{array}{c}\text { Expected } \\
\text { counts }\end{array}$ & Expected \%ages & $\begin{array}{c}\text { Adjusted expected } \\
\text { counts }\end{array}$ & $\begin{array}{c}\text { Adjusted expect- } \\
\text { ed \%ages }\end{array}$ \\
\hline $0-14$ & 299 & $7.64 \%$ & 47804 & $\begin{array}{c}47804^{*} 100 / 360019 \\
=13.28 \%\end{array}$ & $\begin{array}{c}47804^{\star} 3916 / 360019 \\
=519.97\end{array}$ & $\begin{array}{c}519.97^{*} 100 / 3916 \\
=13.28 \%\end{array}$ \\
\hline $15-44$ & 1948 & $49.74 \%$ & 180303 & $\begin{array}{c}180303^{*} 100 / 360019 \\
=50.08 \%\end{array}$ & $\begin{array}{c}180303^{\star} 3916 / 360019 \\
=1961.20\end{array}$ & $\begin{array}{c}1961.20^{*} 100 / 3916 \\
=50.08 \%\end{array}$ \\
\hline $45-64$ & 1076 & $27.48 \%$ & 92825 & $\begin{array}{c}92825^{\star} 100 / 360019 \\
=25.78 \%\end{array}$ & $\begin{array}{c}92825 * 3916 / 360019 \\
=1009.68\end{array}$ & $\begin{array}{c}1009.68 * 100 / 3916 \\
=25.78 \%\end{array}$ \\
\hline $65+$ & 593 & $15.14 \%$ & 39087 & $\begin{array}{c}39087^{\star} 100 / 360019 \\
=10.86 \%\end{array}$ & $\begin{array}{c}39087^{\star} 3916 / 360019 \\
=425.16\end{array}$ & $\begin{array}{c}425.16^{*} 100 / 3916 \\
=10.86 \%\end{array}$ \\
\hline Total & 3916 & $100 \%$ & 360019 & $100 \%$ & 3916 & $100 \%$ \\
\hline
\end{tabular}


Table 3.2.2.2: Observed vs. expected distribution of drug sensitive TB by age groups in DS-TB population of District D.I.Khan $(n=3,916)$

\begin{tabular}{|c|c|c|c|c|c|c|c|c|}
\hline Age groups & $\begin{array}{c}\text { Observed } \\
\text { count }\end{array}$ & $\begin{array}{l}\text { Expected } \\
\text { count }\end{array}$ & O-E & $(O-E)^{2}$ & $x^{2}$ & $\Sigma X^{2}$ & d.f. & $p$-value \\
\hline $0-14$ & 299 & 519.97 & -220.97 & 48827.74 & 93.90 & \multirow{4}{*}{164.61} & \multirow{4}{*}{3} & \multirow{4}{*}{$<.00001$} \\
\hline $15-44$ & 1948 & 1961.20 & -13.19 & 173.98 & 0.09 & & & \\
\hline $45-64$ & 1076 & 1009.68 & 63.32 & 4398.34 & 4.36 & & & \\
\hline $65+$ & 593 & 425.16 & 167.84 & 28170.27 & 66.26 & & & \\
\hline Total & 3916 & 3916 & 00 & & & & & \\
\hline
\end{tabular}

Table 3.2.3.1: Observed, expected and adjusted expected counts and percentages for distribution of drug sensitive TB by type of disease in DS-TB population of District D.I.Khan $(n=3,916)$

\begin{tabular}{|l|c|c|c|c|c|c|}
\hline Type of disease & $\begin{array}{c}\text { Observed } \\
\text { counts }\end{array}$ & $\begin{array}{c}\text { Observed } \\
\% a g e s\end{array}$ & $\begin{array}{c}\text { Expected } \\
\text { counts }\end{array}$ & $\begin{array}{c}\text { Expected } \\
\% a g e s\end{array}$ & $\begin{array}{c}\text { Adjusted expect- } \\
\text { ed counts }\end{array}$ & $\begin{array}{c}\text { Adjusted ex- } \\
\text { pected \%ages }\end{array}$ \\
\hline Pulmonary & 2877 & $\begin{array}{c}2877 * 100 / \\
3916=73.47 \%\end{array}$ & 289265 & $\begin{array}{c}289265 * 100 / \\
360019=80.35 \%\end{array}$ & $\begin{array}{c}289265 * 3916 / \\
360019=3146.39\end{array}$ & $\begin{array}{c}3146.39 * 100 / \\
3916=80.35 \%\end{array}$ \\
\hline Extrapulmonary & 1039 & $\begin{array}{c}1039 * 100 / \\
3916=26.53 \%\end{array}$ & 70754 & $\begin{array}{c}70754 * 100 / \\
360019=19.65 \%\end{array}$ & $\begin{array}{c}70754 * 3916 / \\
360019=769.61\end{array}$ & $\begin{array}{c}769.61 * 100 / \\
3916=19.65 \%\end{array}$ \\
\hline Total & 3,916 & $100 \%$ & 360019 & $100 \%$ & 3916 & $100 \%$ \\
\hline
\end{tabular}

Table 3.2.3.2: Observed vs. expected distribution of drug sensitive TB by type of disease in DS-TB population of District D.I.Khan $(n=3,916)$

\begin{tabular}{|l|c|c|c|c|c|c|c|c|}
\hline Type of disease & Observed count & Expected count & O-E & $(\mathrm{O}-\mathrm{E})^{2}$ & $\chi^{2}$ & $\Sigma \chi^{2}$ & d.f. & p-value \\
\hline Pulmonary & 2877 & 3146.39 & -269.39 & 72570.97 & 23.06 & & \multirow{2}{*}{117.361} & \multirow{2}{*}{$<.00001$} \\
\hline Extrapulmonary & 1039 & 769.61 & 269.39 & 72570.97 & 94.30 & & & \\
\hline Total & 3916 & 3916 & 00 & & & & \\
\hline
\end{tabular}

what we expected from NTP Pakistan ${ }^{7}$ data for year 2018. (Table 3.2.2.2)

3.2.3 Distribution of DS-TB by type of disease (RQ $3 \& \mathbf{H}_{03}$ ): Our observed counts for PTB versus EPTB were 2,877:1,039 $(n=3,916)$ against expected counts of 289,265:70,754 from 360,019 cases of TB from all over Pakistan for year 2018. ${ }^{7}$ With difference in denominators, comparison was not logical. Therefore expected counts and expected percentages were adjusted for our sample size of 3,916 . The expected counts were replaced by 3,146.39:769.61 (adjusted expected). Adjusted expected percentages were same as expected percentages. (Table 3.2.3.1)

Test of significance gave us $\mathrm{p}$-value $<.00001$, rejecting $\mathrm{H}_{03}$, which shows that our observed prevalence $73.47 \%$ for PTB was lower than we expected (adjusted) $80.35 \%$ and our observed prevalence $26.53 \%$ for EPTB was higher than we expected (adjusted) $19.65 \%$ from NTP Pakistan ${ }^{7}$ data for year 2018. (Table 3.2.3.2)

\section{DISCUSSION}

4.1 Distribution of DS-TB by $\operatorname{sex}\left(R Q \quad 1 \& H_{01}\right)$ : Our data $(n=3,916)$ showed that DS-TB was more common in women $53.88 \%(95 \% \mathrm{Cl} 52.32-55.44)$ than men $46.12 \%(95 \% \mathrm{Cl} 44.56-47.68)$.

Similar to our data, two studies showed DS-TB to be more common in women than men; Ashraf, et al. ${ }^{11}$ from Bannu, Pakistan reported distribution of 133 TB patients with $42.86 \%$ men and $57.14 \%$ women, and Zeeshan, et al. ${ }^{12}$ from D.I.Khan reported distribution of 286 drug resistant TB cases as $43 \%$ men and $57 \%$ women.

Opposing our data, seven studies showed DS-TB to be more common in men than women; Barreto, et al. ${ }^{2}$ from Brazil reported distribution of $8,896,314$ cases of TB as $68.45 \%$ men and $31.55 \%$ women, Alene, et al. ${ }^{4}$ from China reported distribution of 471 TB patients, including $70.7 \%$ males and $29.3 \%$ females, Aysel, et al..$^{5}$ from Van city, Turkey showed 411 TB cases as $53.77 \%$ men and $46.23 \%$ women, Venkatesh, et al. ${ }^{6}$ from Gorakhpur, India showed 157 TB cases as $68.8 \%$ men and $31.2 \%$ women, National TB Control Program Pakistan ${ }^{7}$ reported 360,019 TB cases all over Pakistan for year 2018 as $51.72 \%$ men and $48.28 \%$ women, Akhtar, et al. ${ }^{9}$ from Lahore showed 1,250 TB cases with men $53.12 \%$ and women $46.88 \%$ and Wahab, et al. ${ }^{10}$ from Peshawar showed 30 TB 
cases with $56.7 \%$ men and $43.3 \%$ women.

No study could be obtained from literature showing equivalent distribution of DS-TB in males and females.

Our observed prevalence for DS-TB in men $46.12 \%$ was lower than expected (adjusted) $51.72 \%$ and our observed prevalence in women $53.88 \%$ was higher than expected (adjusted) $48.28 \%$ from NTP Pakistan ${ }^{7}$ data for year 2018. (Table 3.2.1.2)

4.2 Distribution of DS-TB by age groups (RQ 2 \& $\mathbf{H}_{02}$ ): Our data showed DS-TB to be most common in age group $15-44$ years $49.74 \%(95 \% \mathrm{Cl} 48.18-51.31)$.

Similar to our study, it was reported to be most common in age group 15-44 years by the following studies; Venkatesh, et al. ${ }^{6}(n=157) 79.7 \%$ in $18-40$ years, NTP Pakistan ${ }^{7}(n=360,019) 50.08 \%$ in $15-44$ years, Akhtar, et al. ${ }^{9}(n=1,250) 79.68 \%$ in $15-45$ years, Wahab, et al. ${ }^{10}(\mathrm{n}=30) 60 \%$ in $20-40$ years, Ashraf, et al. ${ }^{11}(n=133) 41.35 \%$ in $15-45$ years and Zeeshan, et al. ${ }^{12}(n=286) 60.14 \%$ in $15-44$ years.

Our observed prevalence of DS-TB for various age groups was different than we expected from NTP Pakistan data. ${ }^{7}$ (Table 3.2.2.2)

4.3 Distribution of DS-TB by type of disease (RQ $3 \& \mathbf{H}_{03}$ ): Our data revealed that pulmonary TB (PTB) $73.47 \%(95 \% \mathrm{Cl} 72.06-74.83)$ was more common than extrapulmonary TB (EPTB) $26.53 \%(95 \% \mathrm{Cl}$ 25.17-27.94).

Similar to our study, higher prevalence of PTB than EPTB was reported by the following four studies; Pang, et al. ${ }^{3}$ from Beijing, China reported $66.6 \%$ pulmonary and $33.4 \%$ extrapulmonary, National TB Control Program Pakistan ${ }^{7}$ reported $80.35 \%$ pulmonary and $19.65 \%$ extrapulmonary, Akhtar, et al. ${ }^{9}$ from Lahore, Pakistan showed $98.48 \%$ pulmonary and $1.52 \%$ extrapulmonary and Zeeshan, et al. ${ }^{12}$ from D.I.Khan, Pakistan reported $98.60 \%$ pulmonary and $1.40 \%$ extrapulmonary DR-TB.

In contrast to our study, similar prevalence of pulmonary $50.6 \%$ and extrapulmonary TB $49.4 \%$ was reported by Aysel, et al. ${ }^{5}$ from Van city, Turkey.

Our observed prevalence for PTB $73.47 \%$ was lower than expected (adjusted) $80.35 \%$ and our observed prevalence of EPTB $26.53 \%$ was higher than expected (adjusted) $19.65 \%$ from NTP Pakistan ${ }^{7}$ data for year 2018. (Table 3.2.3.2)

\section{CONCLUSIONS}

Drug sensitive tuberculosis was more common in women than men in DS-TB population of District D.I.Khan, Pakistan. It was highest in age group 15-44 years and higher for pulmonary TB than extrapulmonary TB. Our observed prevalence in men was lower than expected and in women it was higher than expected. Our observed prevalence of drug sensitive TB in various age groups was different than expected. Our observed prevalence for pulmonary TB was lower than expected and for extrapulmonary TB it was higher than expected.

Acknowledgement: We are highly thankful to our project supervisor Dr. Muhammad Marwat (marwatmuhammad@gmail.com) to grant us permission to adopt his "Marwat's Logical Trajectory of Research Process" and to help us in data analysis and manuscript writing of this project.

\section{REFERENCES}

1. WHO. Global tuberculosis report 2019. World Health Organization. Geneva [accessed 2020 Dec 15]. Available at: https://apps.who.int/iris/bitstream/ handle/10665/274453/9789241565646-eng.pdf

2. Barreto-Duarte B, Araújo-Pereira M, Nogueira BMF, Sobral L, Rodrigues MMS, Queiroz ATL, et al. Tuberculosis burden and determinants of treatment outcomes according to age in Brazil: A Nationwide Study of 896,314 cases reported between 2010 and 2019. Front Med (Lausanne) 2021 Jul 27;8:706689. https://doi.org/10.3389/fmed.2021.706689

3. Pang Y, An J, Shu W, Huo F, Chu N, Gao M, et al. Epidemiology of extrapulmonary tuberculosis among patients, China, 2008-2017. Emerg Infect Dis. 2019 Mar;25(3):457-64. https://doi.org/10.3201/ eid2503.180572

4. Alene KA, Yi H, Viney K, McBryde ES, Yang K, Bai $L$, et al. Treatment outcomes of patients with multidrug-resistant and extensively drug resistant tuberculosis in Hunan Province, China. BMC Infect Dis 2017 Aug 16;17(1):573. https://doi.org/10.1186/ s12879-017-2662-8

5. Sunnetcioglu A, Sunnetcioglu M, Binici I, Baran Al, Karahocagil MK, Saydan MR. Comparative analysis of pulmonary and extrapulmonary tuberculosis of 411 cases. Ann Clin Microbiol Antimicrob 2015 Jun 24;14:34. https://doi.org/10.1186/s12941015-0092-2

6. Venkatesh U, Srivastava DK, Srivastava AK, Tiwari $\mathrm{HC}$. Epidemiological profile of multidrug-resistant tuberculosis patients in Gorakhpur Division, Uttar Pradesh, India. J Family Med Prim Care 2018 MayJun;7(3):589-95. https://doi.org/10.4103/jfmpc. jfmpc_99_17

7. National TB Control Program, Pakistan. National TB data [cited 2020 Dec 15]. Available at: https:// ntp.gov.pk/national-tb-data/

8. National TB Control Program. National guidelines for control of tuberculosis in Pakistan [revised and updated 2019, cited 2020 Dec 15]. Available at: http://ntp.gov.pk/ntp-old/uploads/National_Guidelines_for_TB_Revised_2019

9. Akhtar AM, Arif MA, Kanwal S, Majeed S. Prevalence and drug resistance pattern of MDR TB in retreatment cases of Punjab, Pakistan. J Pak Med Assoc 2016 Aug; 66(8):989-93.

10. Wahab F, Ashraf S, Khan N, Anwar R, Afridi MZ. Risk factors for multi-drug resistant tuberculosis in patients at tertiary care hospital, Peshawar. J Coll Physicians Surg Pak 2009 Mar; 19(3):162-4. 
11. Khan MA. Prevalence of pulmonary tuberculosis in the District Bannu, Khyber Pakhtunkhwa, Pakistan. Egypt J Chest Dis Tuberc 2021;70:318-22. https:// doi.org/10.4103/ejcdt.ejcdt_97_20

12. Saleem Z, Ullah I, Younis F, Khan N, Awan MSBF, Tauqir J, et al. Distribution of DR-TB by sex, age groups, occupation, province, division, district, type of disease, type of drug resistance, treatment regimen and outcome of treatment in DR-TB population of D.I.Khan Division, Pakistan. Gomal J Med Sci 2020 Jul-Sep;18(3):115-31. https://doi. org/10.46903/gjms/18.03.897

13. Marwat M, Ahmad I, Ashiq F, Ali S, Zamir S, Rehman $\mathrm{MU}$, et al. Frequency, distribution and determinants of diabetes mellitus in adult acute coronary syndrome population of D.I.Khan Division, Pakistan. Gomal J Med Sci 2019 Oct-Dec; 17 (4):131-43. https://doi.org/10.46903/gjms/17.04.2106

14. Ain N, Khan S, Marwat M, Khan N, Ahmad I, Ramzan F, et al. Frequency, distribution and determinants of hypertension in adult stroke population of D.I.Khan Division, Pakistan. Gomal J Med Sci 2019 Jul-Sep; 17 (3):81-9. https://doi.org/10.46903/ gjms/17.03.2076

15. Butt M, Rehman MU, Khan AR, Abrar A. Frequency of triple-vessel coronary artery disease in adult type 2 diabetics versus non-diabetics in coronary artery disease population of Islamabad, Pakistan. Gomal J Med Sci 2019 Apr-Jun; 17(2).37-41. https://doi. org/10.46903/gjms/17.02.2029
16. Shah $S$, Basharat $A$, Shah $M$, Marwat $M$, Billah $M$, Ali SM. Frequency, distribution and presentation $\mathrm{n}$ of hypocalcemia in B-thalassemia major. Gomal J Med Sci 2018; 16:2-8. https://doi.org/10.46903/ gjms/16.01.1446

17. Naqvi SWA, Saeed S, Rafique A, Saeed $M H$, Khan $\mathrm{N}$, Khan A, et al. Prevalence and distribution of malaria by sex, age groups and species in year 2019 in suspected malarial population of district D.I.Khan, Pakistan. Gomal J Med Sci 2020 Oct-Dec; 18(4):0000. https://doi.org/10.46903/gjms/18.04.938

18. Khan A, Khan MI, Ali MA, Hussain A, Ibrahim M, Muhammad T. Sex and age wise distribution, presentation and successful removal and mortality of foreign body aspiration using rigid bronchoscope in children of District D.I.Khan, Pakistan. Gomal J Med Sci 2020 Jan-Mar; 18 (1):3-11. https://doi. org/10.46903/gjms/18.01.1949

19. Raosoft ${ }^{\circledR}$ sample size calculator. [accessed 2020 Dec 15]. Available at: http://www.raosoft.com/ samplesize.html

20. Statistics Kingdom. Proportion confidence interval calculator [internet]. Statistics Kingdom; Melbourne, Australia 2007. [accessed 2020 Dec 15]. Available at: http://www.statskingdom.com/41_proportion_confidence_interval.html

21. Statistics Kingdom. Chi-Square test calculator [internet]. Statistics Kingdom; Melbourne, Australia 2007. [accessed 2020 Dec 15]. Available at: https:// www.statskingdom.com/310GoodnessChi.html

\section{CONFLICT OF INTEREST \\ Authors declare no conflict of interest. GRANT SUPPORT AND FINANCIAL DISCLOSURE None declared.}

\section{AUTHORS' CONTRIBUTION}

The following authors have made substantial contributions to the manuscript as under:

Conception or Design:

Acquisition, Analysis or Interpretation of Data:

Manuscript Writing \& Approval:
AK, AH, SWAN

AK, AH, MW, AR, SAL, SWAN, MF, MZ

AK, AH, MW, AR, SAL, SWAN, MF, MZ

All the authors agree to be accountable for all aspects of the work in ensuring that questions related to the accuracy or integrity of any part of the work are appropriately investigated and resolved. stricted use, distribution \& reproduction in any medium provided that original work is cited properly. 